\section{Zeitsteuerung von Prozessen}

O. Colhoun

Institut für Laboratoriumsmedizin, Klinikum Frankfurt

Höchst, Frankfurt am Main, Deutschland

Englischer Begriff time-controlled processing
Definition Funktionalität eines $>$ Labor-EDV-Systems zur programmierten Ausführung bestimmter Aufgaben zu festgelegten Zeiten oder in bestimmtem Abstand.

Beschreibung Darunter fällt etwa die automatische tägliche Datensicherung im Hintergrund, die mitternächtliche Datenbank-Reorganisation oder z. B. die Festlegung des Ausdrucks einer Resteliste für einen Laborbereich an jedem zweiten Morgen um 9 Uhr auf dem Drucker des für den Bereich verantwortlichen Arztes. 